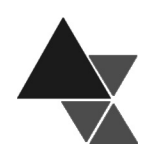

\title{
A Política Brasileira de Segurança Alimentar e Nutricional: concepção e resultados ${ }^{1}$
}

\author{
Walter Belik ${ }^{2}$
}

O artigo discute a utilização do conceito de Segurança Alimentar e Nutricional no desenho do Projeto Fome Zero e a sua implementação a partir de diversos programas que tiveram início na década passada. Essa política pública é o resultado de uma trajetória histórica e de um novo contexto internacional no qual o combate à fome passou a ser associado ao reconhecimento de direitos por parte do Estado. Após apresentar alguns resultados o artigo conclui chamando a atenção para a necessidade de aperfeiçoar programas ligados ao abastecimento, educação alimentar e nutricional e agricultura urbana, de forma a viabilizar o funcionamento de um sistema integrado de Segurança Alimentar e Nutricional.

Palavras-chave: Fome Zero, Segurança Alimentar e Nutricional, Direito Humano à Alimentação.

\section{The Brazilian Food and Nutrition Security Policy: concept and results}

This article discusses the use of the concept of food and nutrition security in the design of the Zero Hunger Project and its implementation through various programs that were initiated in the past decade. This policy is the result of a historical trajectory and a new international context in which the fight against hunger has become associated with the recognition of rights by the state. After presenting some results, the article concludes by stressing the need to improve programs related to supply, nutritional education, and urban agriculture, in order to facilitate the operation of an Integrated System of Food Security and Nutrition.

Key-words: Zero Hunger, Food and Nutrition Security, Human Right to Food.

\footnotetext{
${ }^{1}$ A primeira parte desse texto é uma versão revisada e atualizada do capítulo "Projeto Fome Zero: O Desenho de uma Política de Segurança Alimentar e Nutricional para o Brasil" publicado no Volume I da obra "Fome Zero: uma história brasileira" organizada por A.V. Aranha e publicada pelo Ministério do Desenvolvimento e Combate à Fome em 2010.

${ }^{2}$ Professor Titular do Instituto de Economia e Coordenador do Núcleo de Estudos e Pesquisas em Alimentação (NEPA), UNICAMP. Correspondência: Rua Pitágoras, 353, Barão Geraldo, Campinas, SP. CEP 13083-857.E-mail: belik@eco.unicamp.br.
} 


\section{INTRODUÇÃO}

O conceito de Segurança Alimentar e Nutricional (SAN) é relativamente novo. Tendo como inspiração os modelos de garantia de suprimentos para países em situação de conflito, esse conceito passou a ser utilizado com maior frequência pelos países europeus afetados pela escassez e dependência em relação aos alimentos no início do século $\mathrm{XX}$. No entanto, apesar das elevadas taxas de desnutrição e vulnerabilidade da população brasileira, a SAN só vai entrar no vocabulário das políticas públicas brasileiras nos anos 80. Vale mencionar que a tradição e a inovação dos programas brasileiros de combate à fome introduzidas por Josué de Castro já traziam a marca da Segurança Alimentar. Entretanto, podemos afirmar que o brasileiro Josué de Castro, que transformou o tema da fome em uma bandeira política, não utilizou em sua obra a perspectiva aberta pelo conceito de Segurança Alimentar, talvez por entender que esse fosse um refinamento desnecessário.

Assim, dentro de uma perspectiva brasileira, a SAN passa a fazer parte da linguagem dos planos de governo em período relativamente recentee por uma perspectiva nitidamente de oferta de alimentos. Tendo como ponto de partida a mesma expectativa observada nos países com dificuldades para abastecer a sua população, o mito era de que o Brasil, tolhido por uma inflação galopante, teria grandes dificuldades para expandir a oferta de alimentos. Com isso, em 1985 o Ministério da Agricultura do primeiro governo civil após mais de vinte anos de ditadura militar lança a Política Nacional de Segurança Alimentar, no bojo da retomada do discurso de combate à fome e a carestia, trazido pela Campanha das Diretas ${ }^{3}$ [1], com os objetivos de atender as necessidades alimentares da população e atingir a autossuficiência nacional [2].

O Plano das autoridades da agricultura, tomado de forma abrangente para o espaço nacional, veio se juntar ao esforço desenvolvido no combate à desnutrição, anemia e outras mazelas do crescimento

\footnotetext{
${ }^{3}$ A Campanha das Diretas foi um movimento popular iniciado em 1984 com o objetivo de promover eleições livres diretas, após 20 anos de ditadura militar. Seguindo as regras estabelecidas para a transição para um governo civil, o último presidente militar manteve o dispositivo de exceção democrática fazendo com que o Presidente da República fosse eleito de forma indireta pelo Congresso Nacional, dominado por políticos que apoiavam o regime militar. A Campanha das Diretas pretendia pressionar os parlamentares a aceitarem uma mudança nessas regras levando a eleição de 2004 para as urnas. Apesar das grandes mobilizações de rua, a proposta de mudança da legislação eleitoral não foi aceita, mas o parlamento indiretamente escolheu um presidente civil, dando por encerrado o ciclo militar no Brasil no ano de 1985 .
}

com concentração de renda da década anterior. De fato, em 1976, com a criação do Instituto Nacional de Alimentação e Nutrição (INAN), no âmbito do Ministério da Saúde, estabeleceu-se que a essa organização caberia administrar os Programas Nacionais de Alimentação e Nutrição que reuniriam uma série de ações articuladas na área da alimentação do trabalhador, escolares, gestantes, compra direta do produtor, vigilância sanitária e nutricional e outros. Segundo L'Abbate [3], a criação do INAN foi na realidade uma forma de substituir a influência que Josué de Castro - vivendo no exílio, ainda mantinha sobre a Comissão Nacional de Alimentação (CNA) criada nos anos 40 e operante. Boa parte dos programas desenhados no âmbito da CNA, como a merenda escolar e a alimentação do trabalhador, foram mantidos e aperfeiçoados pelo INAN, muito embora houvesse uma preocupação nova de focalizá-los em públicos específicos ${ }^{[1]}$.

Esses dois pilaresda política de segurança alimentar, a oferta de alimentos e a nutrição, tomaram corpo com a realização da I Conferência Nacional de Alimentação e Nutrição e da 8 a Conferência Nacional de Saúde, promovidas pelo governo com a participação de representantes da sociedade civil em 19864. Nesse mesmo período a sociedade vivia o agravamento da situação nutricional das famílias provocada pela hiperinflação e pelos sucessivos planos econômicos com congelamento de ativos. Mas, ao mesmo tempo, um intenso debate político se delineava e esse iria definir o formato e os rumos da nova Constituição Federal. Os dois eventos mencionados marcaram os debates do Congresso Constituinte, sendo aprovada a criação do Sistema Único de Saúde (SUS), proposto na Conferência Nacional de Saúde e atendendo a necessidade de reconhecimento do Direito à Saúde. Por outro lado, o tema da Segurança Alimentar e o reconhecimento do Direito à Alimentação, que seria garantido pela criação de um Sistema de Segurança Alimentar e Nutricional (SISAN), que estava presente na discussão da nova Constituição, não foi sequer analisado e não saiu do papel [4,5].

Dessa maneira, o artigo 6 o da Constituição Federal, promulgada em 1988, estabelece que:

\footnotetext{
${ }^{4}$ Essa conferência foi assim denominada a partir de um desdobramento de uma das áreas temáticas da 8 a Conferência Nacional de Saúde. Foi produzido um extenso documento de 15 páginas com recomendações para o governo e a Assembleia Nacional Constituinte, que iniciava os seus trabalhos. Nesse documento há mais de uma centena de propostas que vão desde a forma de operar o congelamento de preços dos gêneros de primeira necessidade até a criação de um Sistema de Segurança Alimentar e Nutricional à semelhança do que estava sendo proposto para a Saúde.
} 
São direitos sociais a educação, a saúde, o trabalho, o lazer, a segurança, a previdência social, a proteção à maternidade e à infância, a assistência aos desamparados, na forma desta Constituição.

Como se observa, o tema da alimentação não teria sido mencionado na nova constituição, muito embora o Brasil tivesse sido signatário do International Covenant on Economic, Social and Cultural Rights que já reconhecia o "direito fundamental de estar livre da fome” em 1976. Décadas mais tarde, em 2010, o texto constitucional acabou sendo alterado por meio da Emenda Constitucional 64 acrescentando a palavra "alimentação" em seguida à referência ao Direito à Saúde, contemplando, portanto, a demanda estabelecida pela Conferência de Alimentação e Nutrição, realizada em 1986, quase 25 anos depois.

Transformado em direito pela lei brasileira, estabelece-se um novo patamar institucional para as políticas de segurança alimentar no Brasil, permitindo consolidar os resultados alcançados ao longo dos últimos anos. Desta forma, o objetivo desse texto é o de apresentar detalhadamente as inovações trazidas pelo Fome Zero demonstrando que ele se diferencia das demais políticas que o antecederam. Essa distinção aparece de forma clara de diversas maneiras, mas pretendemos destacar dois aspectos principais, a saber:

a) O Fome Zero foi concebido como uma verdadeira política de Segurança Alimentar, incorporando o aspecto mais moderno desse conceito e levando em consideração a necessidade de universalizar a ação do Estado abrindo espaço para o reconhecimento de direitos;

b) Enquanto política, o Fome Zero apresenta uma articulação entre os seus programas que difere diametralmente dos programas focalizados e isolados do período anterior.

Pretendemos também dirigir um olhar para os desafios que se apresentam daqui para frente, tendo plena consciência que o Fome Zero não conseguiu resolver satisfatoriamente alguns dos problemas a que o seu projeto havia relacionado.

O texto a seguir registra uma breve descrição dos debates que precederam a preparação do Fome Zero, demonstrando que este foi o resultado de um acúmulo de conhecimentos que haviam se articulado desde os anos 80 com as Conferências de Saúde e, mais tarde, com o projeto do Governo Paralelo e as discussões da I Conferência Nacional de Segurança Alimentar e Nutricional de 1994. A preparação do Fome Zero se beneficiou também da mobilização social ocorrida com o trabalho do sociólogo Betinho no comando da Organização "Ação da Cidadania" e mais tarde com a criação do Fórum Brasileiro de Segurança Alimentar e Nutricional.

O presente trabalho se divide em mais três seções:

(1) descrição dos elementos principais do Projeto Fome Zeroenfatizando a sua lógica interna;

(2) análise de como este projeto poderia ser repensado à luz dos novos debates que surgiram sobre a SAN nos últimos anos; e

(3) sinalização de alguns tópicos para aperfeiçoamento da Política de Segurança Alimentar e Nutricional agora sob um guarda-chuva institucional consolidado.

\section{DEBATES SOBRE A SEGURANÇA ALIMENTAR E NUTRICIONAL (SAN) NOS ANOS 90}

O ponto de partida para a utilização do conceito moderno sobre a SAN foi a Conferência Internacional sobre Nutrição realizada em 1992, sob o patrocínio da Organização das Nações Unidas (ONU) e que definiu um plano de ação direta para o combate à fome ao redor do mundo. Nos documentos de trabalho e na declaração final desse encontro apresentou-se uma estratégia de atuação da comunidade internacional na qual estavam contemplados nove temas. Essa temática visava atender as questões emergenciais de saúde para o combate à desnutrição assim como as ações preventivas no campo do saneamento e da saúde pública. Havia também uma preocupação geral quanto à qualidade do alimento consumido pela população e a segurança alimentar nos domicílios e na comunidade de forma a tornar mais explícitas as ligações entre nutrição e desenvolvimento agrícola 5 .

\footnotetext{
${ }^{5}$ Ver a respeito:

http://www.fao.org/docrep/V7700T/v7700t02.htm\#TopOfPage
} 
No plano internacional, seguiu-se a essa conferência a Cúpula Mundial de Alimentação, que se reuniu em Roma em 1996 e estabeleceu as metas de redução do número de pessoas subnutridas no planeta. O grande avanço observado nessa reunião foi o de que, ao mesmo tempo em que a Food and Agriculture Organization (FAO) ${ }^{[6]}$ trabalhava as metas para a redução da subnutrição, passou-se também a focar questões referentes à qualidade dos alimentos e aos padrões de consumo alimentar. Como se observa no primeiro parágrafo do Plano de Ação aprovado nessa reunião, e que contou com a participação de 180 países, foi estabelecida uma definição mais abrangente de SAN, a saber:

Existe segurança alimentar quando as pessoas têm, a todo o momento, acesso físico e econômico a alimentos seguros, nutritivos e suficientes para satisfazer as suas necessidades dietéticas e preferências alimentares, a fim de levarem uma vida ativa e sã (1996) ${ }^{6}$.

Em seguida:

Para melhorar o acesso aos alimentos é imprescindível erradicar a pobreza. A grande maioria das pessoas subalimentadas não pode produzir alimentos, ou mesmo comprá-los, em quantidade suficiente (1996).

$\mathrm{Na}$ declaração final do encontro aparece o compromisso dos países com a alimentação adequada e com a garantia do direito fundamental de todos a não ter fome, como declarado no Pacto Internacional sobre Direitos Econômicos, Sociais e Culturais firmado em 1996(compromisso no 7) 7 .

A Cúpula Mundial da Alimentação foi um marco no sentido de estabelecer que a Segurança Alimentar deveria ser abordada em três níveis: das nações, do domicílio e dos indivíduos. Ademais, de forma implícita, a Segurança Alimentar comportaria quatro dimensões de atuação para as políticas públicas: a disponibilidade, o acesso, a estabilidade e a utilização

\footnotetext{
${ }^{6}$ Plano de Ação da Cúpula Mundial de Alimentação, FAO, Roma; 1996 [6].

7 "Nós, Chefes de Estado e de Governo ou os nossos representantes, reunidos na Cúpula Mundial da Alimentação a convite da Organização das Nações Unidas para a Alimentação e a Agricultura (FAO), reafirmamos o direito de todos a terem acesso a alimentos seguros e nutritivos, em consonância com o direito a uma alimentação adequada e com o direito fundamental de todos a não sofrer a fome" (Declaração de Roma, 1996) [6].
}

dos alimentos. Merece destaque também o fato de que há nessa declaração uma associação clara entre pobreza e subnutrição, ao mesmo tempo em que se atribui ao Estado a responsabilidade pela garantia do Direito Humano à Alimentação. Outro elemento importante a ressaltar é a adoção do termo "alimentação adequada" abrindo espaço para a incorporação do termo "soberania" à questão dos alimentos.

Mais à frente, saindo do campo da semântica e das declarações diplomáticas e entrando na vida real, nessa mesma época, novas práticas eram testadas e difundidas no Brasil e nos demais países do mundo e viriam a influenciar diretamente a construção e o rumo dos programas sociais da década seguinte no Brasil. São duas as iniciativas que merecem ser mencionadas e que serão discutidas de forma mais detalhada: a introdução dos programas municipais de transferência de renda para combater a pobreza (em Campinas entre 1993 e 1996, em Brasília no período de 1995 a 1998 e em Recife de 1997 a 2000) e o programa integrado de produção e consumo de alimentos iniciado pela Prefeitura de Belo Horizonte (1993-96).

\section{TRANSFERÊNCIAS DE RENDA}

Os programas de transferência de renda introduzidos no Brasil nos anos 90 tinham como fontes recursos próprios, fruto de recolhimentos tributários locais. Esses recursos eram repassados às famílias cadastradas ou em situação de risco, estabelecendo condicionalidades na área da saúde, educação e capacitação profissional. A essas localidades pioneiras mencionadas agregaram-se outros municípios como São Paulo e Ribeirão Preto, localizada no interior do Estado de São Paulo [7. Em 1997, foi aprovada a Lei Federal 9.533 autorizando o Poder Executivo a conceder recursos aos "Municípios que instituírem programas de garantia de renda mínima associados a ações socioeducativas". Mais tarde, no ano de 2000, o Governo Federal aprovou também a Emenda Constitucional no 31 instituindo o Fundo de Combate à Pobreza a ser formado por recursos de alíquotas de impostos e por contribuições fiscais, assim como por transferências do Tesouro e recursos da venda de empresas estatais. Esses recursos e os bons resultados aferidos com os programas pioneiros levaram a sua rápida disseminação.

No plano federal, as críticas aos velhos programas assistencialistas de frentes de trabalho ou de doação de cestas básicas [8] e a nova fonte de recursos 
disponível deram origem ao programa Bolsa Escola Federal, em 2001, nos moldes dos programas municipais de transferência de renda. Inspirado pelos técnicos do Banco Mundial que estiveram no Brasil analisando os programas municipais, foi lançado no México o Programa de Educação, Saúde e Alimentação (PROGRESA), em 1997. Esse programa, que foi pioneiro na América Latina, fez uso da transferência de recursos fiscais resultantes da eliminação do chamado subsídio da tortilla ${ }^{8}[9]$. Em seguida foram criados programas semelhantes em Honduras, Nicarágua, Colômbia, Equador, Jamaica, Argentina e Chile [7,10].

A discussão em torno do lançamento do Fome Zero, no entanto, teve como inspiração os programas de transferência de renda vinculados à compra de alimentos nos moldes do Programa Food Stamp norte-americano. Esse programa tinha como base a ajuda alimentar concedida às famílias carentes durante a Grande Depressão dos anos 30, sendo que nesse período havia uma preocupação em reativar a atividade econômica sem deixar que os preços agrícolas caíssem para níveis críticos. A distribuição de alimentos por meio de cupons continuou como política estadual em alguns estados da União, até o final dos anos 50. Em 1960, o presidente Kennedy transforma essa iniciativa em programa federal. Aprovado pelo Congresso Americano em 1964, o Food Stamp passou a ser "adquirido" pelos beneficiários que pagavam pelo selo um valor proporcional a sua condição financeira.

O caráter diferenciado do Programa Food Stamp era o de que ele permitia o fechamento do circuito da renda nas localidades onde a população carente teria acesso ao benefício. Desta forma a transferência de renda seria canalizada diretamente para as compras de alimentos, criando mercado ao produtor e ao pequeno comércio e elevando a renda das localidades deprimidas. Ao final dos anos 90, os Estados Unidos contabilizavam um total de 20 milhões de beneficiários do sistema e os trabalhos divulgados pelo Departamento da Agricultura, gestor do programa, mostravam os bons resultados alcançados em termos do aumento no consumo e melhor percepção quanto à Segurança Alimentar?. Por outro lado, também eram

\footnotetext{
${ }^{8}$ Uma das exigências para o México se integrar ao NAFTA (Tratado de Livre Comércio da América do Norte), assinado em 1994.

${ }^{9}$ Se uma família não tiver renda, pode receber o equivalente a até US\$ 341 por mês (concedidos para uma família de três pessoas no ano de 2001). Em 2000, o benefício médio mensal foi de US\$ 73 por pessoa e quase US\$ 173 por família. Os cupons não podem ser trocados por dinheiro. Além disso, não podem ser utilizados para comprar álcool, cigarro e itens não alimentares. Existe uma fiscalização rigorosa nos estabelecimentos de varejo que trabalham com os cupons. Os desvios
}

apontados problemas, entre eles a falta de integração entre o Food Stamp e outros programas sociais como o de Alimentação Escolar, Apoio à Gestantes e Nutrizes, Apoio à Idosos, Educação Alimentar, entre outros [11].

Diante desse contexto e como destaque vale mencionar o interesse que se cercava em relação às avaliações sobre a operação do Programa Nacional do Leite para Crianças Carentes (PNLCC) no Brasil. Esse programa inovou ao criar o atendimento direto ao público carente por meio da doação de cupons para a compra de leite diretamente no comércio local, espelhando o bem sucedido programa Food Stamps norte-americano. O ticket do leite, como era conhecido popularmente, teve duração efêmera, mas deve se destacar a sua abrangência nacional, chegando a atender cinco milhões de crianças em 259 municípios com um incremento na oferta desse produto da ordem de três milhões de litros/ano ${ }^{[12]}$. Na época, esse programa foi muito criticado por problemas relacionados ao desvio dos cupons, à criação de um mercado paralelo de papéis e ao clientelismo na escolha do público elegível [13]. No entanto, alguns estudos mostraram resultados muito favoráveis em termos de melhora na nutrição das crianças e apoio à produção pecuária local [14].

\section{ABASTECIMENTO DE ALIMENTOS}

As questões ligadas ao abastecimento representavam um desafio para as discussões sobre a Segurança Alimentar. Por um lado, era necessário dissociar a Segurança Alimentar do tratamento exclusivo que privilegiava a produção e distribuição de alimentos, segundo a ênfase atribuída pelos técnicos do Ministério da Agricultura e pela FAO até os anos 80. Por outro lado, as condições de produção e distribuição de alimentos haviam se transformado rapidamente nos 10 anos anteriores e as propostas continuavam as mesmas da década anterior.

Para ilustrar essa dicotomia vamos tomar o diagnóstico e algumas propostas apresentadas no texto do Governo Paralelo "Política Nacional de Segurança Alimentar" de outubro de 1991 elaborado por José Gomes da Silva e Luiz Inácio Lula da Silva. Embora o texto se revelasse muito mais avançado em relação a outras contribuições devido a sua abordagem intersetorial, havia uma ênfase nas questões da

são punidos com descredenciamento, processos civis e até mesmo com o fechamento do estabelecimento. 
produção agropecuária, considerada "insatisfatória e instável" [15] e na redução do espaço do comércio tradicional. Para a solução desses problemas se propunha um conjunto de intervenções desde a intensificação da reforma agrária até a "descartelização do setor e a indução à concorrência” [16]. Não há dúvida que as propostas do Governo Paralelo eram avançadas e, não por acaso, serviram de base para a proposta do Projeto Fome Zero. No entanto, no tocante à questão do abastecimento, os anos 90 foram um período de profundas transformações. Em um curto espaço de tempo - na virada dos anos 90 - ocorreu o desmonte do sistema atacadista representado pelo Sistema Nacional de Centrais de Abastecimento (SINAC) e pela Companhia Brasileira de Alimentos (COBAL). Nesse período, os preços se estabilizam com taxas de crescimento inferiores a dois dígitos e as grandes cadeias de supermercados passam a dominar o mercado. Do ponto de vista da produção agrícola, ocorre também um salto. A produção de grãos e oleaginosas, por exemplo, saiu de um patamar histórico de 50 milhões de toneladas (safra 1990/91) para 100 milhões de toneladas (safra 2000/01) embora se possa mostrar que parte importante desse aumento foi devido ao crescimento da produção de soja.

A Política Municipal de Abastecimento de Belo Horizonte (capital do Estado de Minas Gerais com 2,3 milhões de habitantes em 2000), por sua vez, representou uma fonte de influência para a reformulação dos programas isolados de abastecimento do tipo feirão, varejão, sacolão e comboios de alimentos que haviam sido desenhados nos anos 70 . Em Belo Horizonte, a Secretaria Municipal de Abastecimento passou a nuclear 18 programas de forma articulada [16], exercendo atividades de regulação (preços, qualidade, fluxos comerciais, parcerias etc.), intervenção compensatória (restaurantes populares, doações para instituições, alimentação escolar) e educação e transmissão de práticas alimentares (educação alimentar, redução de sobras, agricultura urbana e outros). O programa de Belo Horizonte foi inovador, mas nem por isso deixou de incorporar as boas experiências de abastecimento. Estudos demonstraramque o custo de implementação desses programas foi relativamente baixo se consideradas a escala de atendimento e a articulação das ações. Mesmo assim, a experiência demonstrou que haveria espaço para maiores reduções de custo e melhor focalização $[17,18]$.
De modo geral, a nova política de abastecimento deveria incorporar as mudanças que ocorreram ao longo da década no campo da macroeconomia e no que se refere ao desenvolvimento empresarial. $\mathrm{Na}$ virada do século já havia se consolidado a estabilização de preços e, portanto os mecanismos de congelamento utilizados anteriormente já não eram necessários. Ao mesmo tempo, o esforço público de fiscalização em relação aos preços poderia ser dirigido para os aspectos sanitários ou das condições dos trabalhadores do setor. Da mesma maneira, havia crescido sobremaneira o peso da Grande Distribuição no varejo de alimentos [19]. Por meio da instalação de plataformas de distribuição e de negociações diretas com os produtores e fornecedores da agroindústria as cadeias de supermercados avançaram terreno em relação ao varejo tradicional reduzindo o papel das CEASAs (Centrais Públicas de Abastecimento, criadas nos anos 70) e dos equipamentos montados na década anterior. O grande desafio era, portanto, desenvolver uma política de abastecimento para as áreas urbanas que pudesse atuar em sintonia e sem enfrentamento com a Grande Distribuição e atender a população, preservando os hábitos alimentares locais.

\section{O DESENHO DO PROJETO FOME ZERO}

O Projeto Fome Zero - Uma Proposta de Política de Segurança Alimentar para o Brasil, lançado em 2001 e resultado de um trabalho coletivo no qual participaram quase uma centena de técnicos e especialistas, procurou contemplar as questões levantadas anteriormente e se apresentar de forma didática ao grande público. Lamentavelmente, muitas vezes esse didatismo acabou sendo simplificado ao extremo e o Fome Zero se transformou para muitos e para a imprensa não especializada em uma grande campanha de doações. Outros programas específicos que também chamam a atenção no Projeto Fome Zero, entre os mais de 40 que se pretendia implementar no novo governo, são as doações de cestas básicas emergenciais para públicos específicos como os assentados da Reforma Agrária e a Educação Alimentar que seria introduzida no curriculum do ensino fundamental.

Analisando-se a lógica interna do Fome Zero podemos observar que a proposta se apresentava em três níveis: estrutural, específico para alimentação e local. 
No nível estrutural estavam as políticas mais gerais voltadas para as transformações das condições de vida da população e pela manutenção das conquistas que seriam obtidas com os avanços proporcionados pelo crescimento econômico, distribuição de renda e reformas no mercado de trabalho propugnadas pelo Instituto Cidadania ${ }^{10}$. Vale lembrar que o Fome Zero era o segundo grande projeto de trabalho desenvolvido pelo Instituto Cidadania que já havia lançado o Projeto Moradia, visando apresentar uma proposta para as questões de habitação no Brasil. No mesmo ano do Projeto Fome Zero, o Instituto Cidadania lança também o Projeto Segurança, tratando do problema da segurança pública no Brasil. Mais tarde, foi desenvolvido também o Projeto Juventude com propostas para a educação, capacitação profissional e absorção dos jovens no mercado de trabalho.

No nível específico foram apresentadas ações voltadas para o aumento da oferta de alimentos, a facilidade de acesso da população a esses alimentos e todos os aspectos ligados à qualidade. Nesse nível concentravam-se as propostas voltadas para o apoio emergencial ao público vulnerável à insegurança alimentar. A realização de programas vinculados a esses dois primeiros níveis davam a dimensão daquilo que a Organização das Nações Unidas para a Agricultura e Alimentação (FAO) denomina de twin track strategy, ou seja, a combinação de ações emergenciais ${ }^{11}$ e estruturais contra a fome.

Finalmente, no nível local eram examinadas condições peculiares das áreas urbanas metropolitanas e não metropolitanas e das áreas rurais. Em todas essas, eram propostas ações desenvolvidas a partir da participação de atores locais analisando-se as condições institucionais diferenciadas para a sua implementação. A Figura 1 apresenta de forma resumida a aplicação do conjunto de programas proposto pelo Fome Zero.
Observa-se pelo diagrama que o Programa Bolsa Escola ${ }^{12}$ se apresenta como uma política estrutural de sustentação da renda das famílias, com as contrapartidas necessárias, transitando para um esquema de Renda Mínima, nos moldes do que havia sido proposto pelo Senador Eduardo Suplicy no Senado Federal em 1991, tendo sido aprovado somente em 2004. No Projeto Fome Zero, o apoio à Renda Mínima aparecia ao lado de outros programas estruturais como a Reforma Agrária e a Geração de Emprego e Renda. É interessante destacar que o documento do Instituto Cidadania separou o Bolsa Escola do novo programa de transferência de renda condicionada que se pretendia implementar que era o Cupom-Alimentação, depois transformado no CartãoAlimentação. Esse novo programa, como foi mencionado, tinha objetivos alimentares no sentido de superar as deficiências colocadas pelos programas de nutrição até então implementados pelos governos.

No início da década 2000, até o lançamento do Fome Zero, o principal programa de alimentação do país estava sob gestão do Ministério da Saúde e era desenvolvido de forma terceirizada por uma organização ligada à Igreja Católica. Nesse período, havia uma grande controvérsia em relação à efetividade desse programa, denominado de multimistura e desenvolvido pela Pastoral da Criança. Esse programa, gerenciado por uma organização de fora do governo, recebia $70 \%$ das suas verbas a partir de transferências do Ministério da Saúde, o restante era proveniente de campanhas veiculadas no principal canal de TV visando arrecadar dinheiro para as crianças ${ }^{13}$. Em relação a esse programa, os críticos do trabalho da Pastoral argumentavam que o suplemento multimisturapreparado à base de folhas de mandioca, pó de casca de ovo e farelos de arroz e trigo e administrado para crianças recém-nascidas - teria algum efeito apenas para aqueles que estivessem em situações mais críticas. Ademais, havia uma grande preocupação de outras igrejas quanto ao uso do programa da Pastoral com objetivos de proselitistas, haja vista que todos os meses eram organizadas reuniões nas quais se rezavam missas e veiculava-seorientações católicas às mães beneficiárias.

Com isso, o Cartão-Alimentação funcionaria como um programa de transferência de renda com

\footnotetext{
12 Programa de Transferência de Renda Condicionada à frequência escolar executado em nível federal a partir de 2001 para um conjunto restrito de familias em situação de pobreza.

${ }^{13}$ Vale mencionar que os canais de TV no Brasil funcionam sob concessão do Governo Federal.
} 
curso forçado para o seu uso na alimentação, ou seja, com um perfil totalmente diferente do antigo Bolsa Escola. O primeiro tinha como objetivo direto fazer com que as pessoas se alimentassem melhor, ao passo que o Bolsa Escola era voltado para a promoção de mudanças estruturais com a redução da pobreza intergeracional. Além disso, o Cartão-Alimentação pressupunha uma estrutura diferenciada a partir da organização de Comitês Gestores locais que zelariam pelo desenvolvimento local no estilo "keynesiano", enquanto o Bolsa Escola manteria uma estrutura centralizada de concessão e acompanhamento dos beneficiários.

Outros programas específicos que também chamam a atenção no Projeto Fome Zero, entre os mais de 40 que se pretendia implementar no novo governo, são as doações de cestas básicas emergenciais para públicos específicos como os assentados da Reforma Agrária e a Educação Alimentar que seria introduzida no curriculum do ensino fundamental.

Figura 1. Esquema das propostas do Projeto Fome Zero

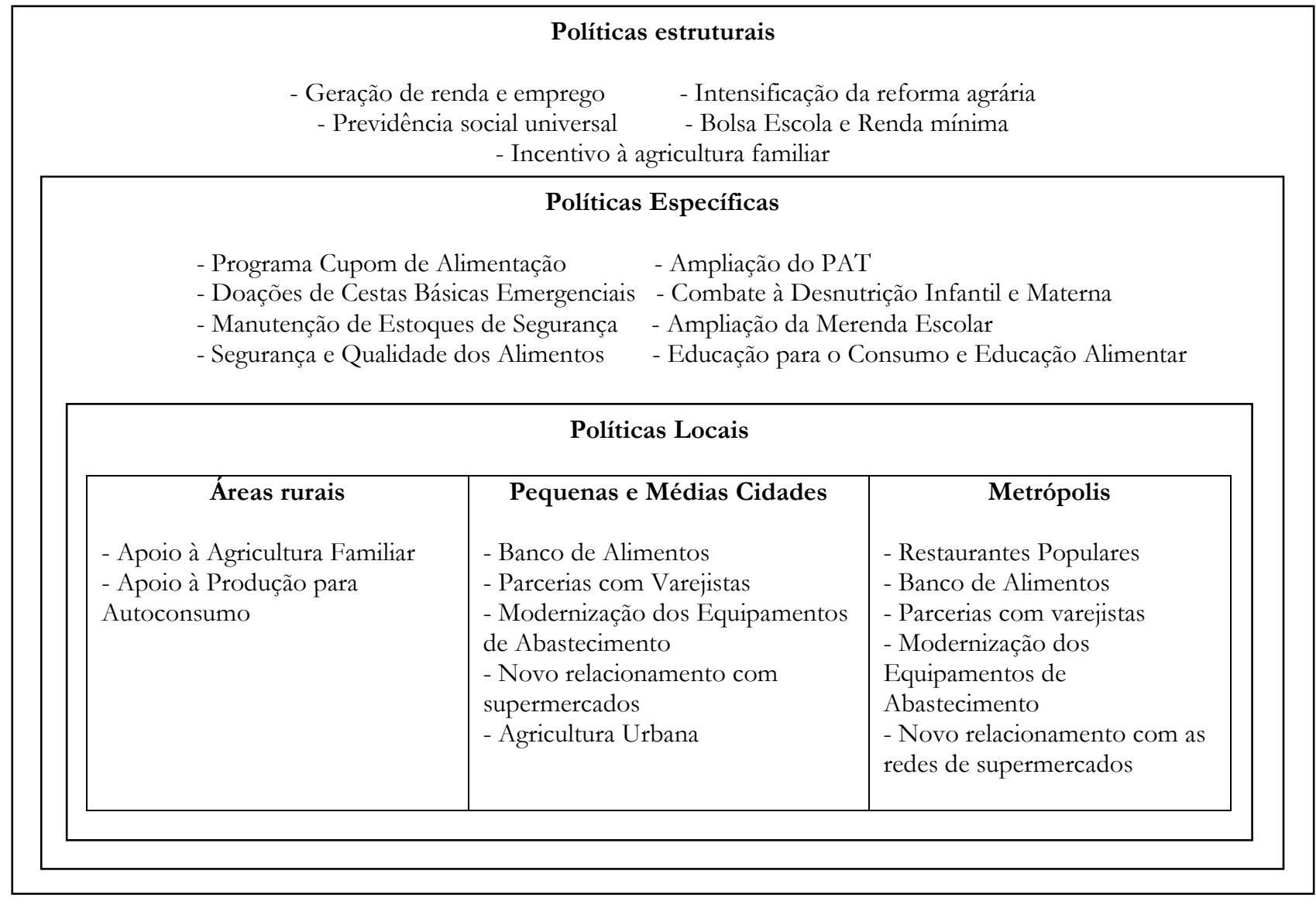

Fonte: Instituto Cidadania, 2001[12].

No campo dos programas locais, deve ser destacado o novo relacionamento que se propunha estabelecer junto aos varejistas e distribuidores. Essa proposta partia da constatação de que o varejo moderno estava muito bem estruturado nas cidades médias e grandes e que seria um contrassenso criar mecanismos paralelos para a garantia de abastecimento.
A proposta era de que as redes de supermercados poderiam apoiar a venda de produtos populares ou mesmo produtos da agricultura familiar em troca de isenções fiscais. Havia dois exemplos bem sucedidos verificados nos anos 90 nesse sentido: a trajetória da Empresa Baiana de Alimentos (EBAL), que logrou colocar toda uma ala de produtos populares nos 
supermercados do Estado da Bahia e o Programa de Verticalização da Pequena Produção Familiar (PROVE) desenvolvido no governo Cristovam Buarque, no Distrito Federal, que visava promover a venda de produtos locais nos grandes supermercados de Brasília.

Havia também entre as ações locais uma proposta de grande alcance que visava disseminar a instalação dos Bancos de Alimentos por todas as cidades médias e grandes do Brasil. Tratava-se de uma proposta em construção, pois não estava claro como o governo poderia participar diretamente desse esforço tendo em vista que a operação dos bancos deveria ser feita diretamente pelas empresas produtoras e distribuidoras de alimentos além das Organizações Não Governamentais (ONGs) envolvidas. A grande dificuldade estava em envolver as prefeituras e o Governo Federal nas atividades de solicitar e administrar as doações e do controle do desperdício. Em todos os exemplos estudados e implementados em outros países esse trabalho era desenvolvido por ONGs com baixa participação do governo. Inclusive no Brasil, os incipientes bancos de alimentos eram ONGs ou instituições privadas administradas de forma independente. Caberia, portanto, ao governo, regular o funcionamento do setor e incentivar a sua fluidez, garantindo as doações e a qualidade dos alimentos que chegariam às instituições beneficiadas. Nesse sentido, o projeto Fome Zero destacacomo atividade principal a aprovação pelo Congresso Nacional do Projeto de Lei 4.747/1998, conhecido como o Estatuto do Bom Samaritano, instrumento pelo qual se poderiam facilitar as doações e reduzir o desperdício na cadeia produtiva.

Finalmente vale destacar o Programa de Restaurantes Populares cujo objetivo era o de promover a alimentação saudável por apenas $\mathrm{R} \$ 1,00$ para as massas de trabalhadores que circulavam pelo centro das metrópoles e grandes cidades. A experiência tinha sido exitosa - com a atuação por meio de grandes instalações - em locais de muita circulação nas cidades de Belo Horizonte e Rio de Janeiro. Nessas cidades, restaurantes de grandes dimensões, instalados no entorno dos terminais rodoviários e ferroviários serviam até 5.000 refeições por dia para todos os cidadãos, sem cadastramento ou qualquer outro tipo de focalização. As refeições eram de alta qualidade, servidas em pratos, com talheres e em refeitórios com grande área. Tendo em vista o baixo subsídio decorrente dessa política e o admirável impacto social, o programa foi incorporado ao Fome Zero com metas ambiciosas.

Para a instalação do Fome Zero, considerando-se os seus principais programas, a equipe de trabalho fixou algumas metas preliminares e calculou o total de recursos necessários para a sua execução. O montante estimado era de US\$ 8 bilhões por ano por oito anos para os três níveis de governo e as fontes de financiamento, de fato, existiam. Esses recursos estariam dispersos no orçamento federal sem que fossem usados para o seu propósito, como era o caso do Fundo de Combate à Pobreza.

Examinando retrospectivamente podemos reconhecer a boa articulação entre os programas propostos e uma clara visão de como obter sinergia em termos orçamentários e operacionais em um eventual programa de governo a partir do Projeto Fome Zero. Havia também, já nessa fase, a incorporação da noção de reconhecimento de Direitos ao projeto, o que não estava explícita no programa do Governo Paralelo e não estava presente na mobilização encabeçada pelo sociólogo Betinho no início dos anos 90.

A partir de 2011 toma posse a Presidente Dilma Rouseff e com o objetivo de aprofundar a Política Social anterior lança o Plano Brasil sem Miséria (PBSM). Considerando que a pobreza tem um aspecto multidimensional, o novo plano está tentando atingir aquela parte da pobreza que se encontra não identificada. Considerando que a pobreza não é apenas uma questão de renda, o novo PBSM está buscando as famílias em situação de vulnerabilidade de maneira a resgatá-las através de um novo conjunto de ações. Levantamentos preliminares do governo demonstraramque haveria ainda um contingente de 16 milhões de pessoas em condições de extrema pobreza sem qualquer assistência oficial. Esses pobres não integravam cadastros públicos e as autoridades de saúde e educação não conseguiam fazer chegar a esse público os seus programas. O PBSM trabalha com três objetivos simultâneos: elevar a renda, estender serviços e cidadania e promover a inclusão produtiva das famílias em extrema pobreza.

Considerando como prioridade essa camada da extrema pobreza, o novo governo resolveu aprofundar alguns importantes programas na área de infraestrutura como o acesso à energia elétrica e a construção de cisternas para o consumo de água potável. No campo da transferência de renda, houve 
um aumento nos valores do Bolsa Família, na quantidade de filhos com possibilidade de inclusão e com a extensão do benefício a filhos adolescentes. Finalmente, no que tange aos programas de inclusão produtiva, o governo reforçou uma série de programas na área rural - entre estes os programas de compras institucionais para a alimentação escolar e entidades de assistência social. $\mathrm{Na}$ área urbana foram delineados novos programas de capacitação técnica, microcrédito e desburocratização para abertura de pequenos negócios.

\section{RESULTADOS ALCANÇADOS}

A velocidade com a qual os programas do Fome Zero foram implementados permitiu que alguns indicadores de vulnerabilidade pudessem ser revertidos rapidamente no Brasil. Houve uma redução significativa da pobreza em termos relativos e a concentração de renda medida pelo Índice Gini também mostrou uma queda. A explicação para essas mudanças pode ser encontrada não apenas no esforço que foi realizado em termos de política social, mas também a partir de medidas de política econômica que impactaram diretamente no crescimento, gerando mais empregos, promovendo maiores salários e levando a um círculo virtuoso de prosperidade.

Nos últimos dez anos a população brasileira cresceu em 22 milhões de habitantes, a proporção de pessoas com mais de 60 anos saltou de 9,0\% em 2000 para 12,1\% em 2011, o que está diretamente ligado com a redução nas taxas de fecundidade para 1,86 filhos por mulher segundo o Censo de $2010 \mathrm{em}$ comparação com 2,38 filhos por mulher em 2000. Houve também um importante crescimento da urbanização, sendo que $84,4 \%$ da população residiamem áreas urbanas.

No projeto original do Fome Zero colocava-se a necessidade de gerar crescimento e melhorar o nível do salário real. Em termos macroeconômicos, o Brasil experimentou um crescimento acelerado no período 2002-2010. Considerando o PIB nominal pelo valor médio da taxa e câmbio, os valores saltaram de US\$ 504 bilhões em 2002 para US\$2.089 bilhões em 2012 e a renda per capita em dólares variou no mesmo período de US\$ 3.760 para US\$ 11.082, utilizando-se os mesmos critérios de PIB nominal e taxa de câmbio média.

Mas, além da ilusão estatística proporcionada por um dólar depreciado durante a década podemos verificar um crescimento expressivo do salário mínimo em termos reais. Como se observa na Figura 2, ao longo da década passada o governo promoveu a recuperação do salário mínimo por meio de aumentos reais que permitiram um maior poder de compra ao trabalhador.

Figura 2. Brasil: Evolução real do salário mínimo (Base maio de 2012)

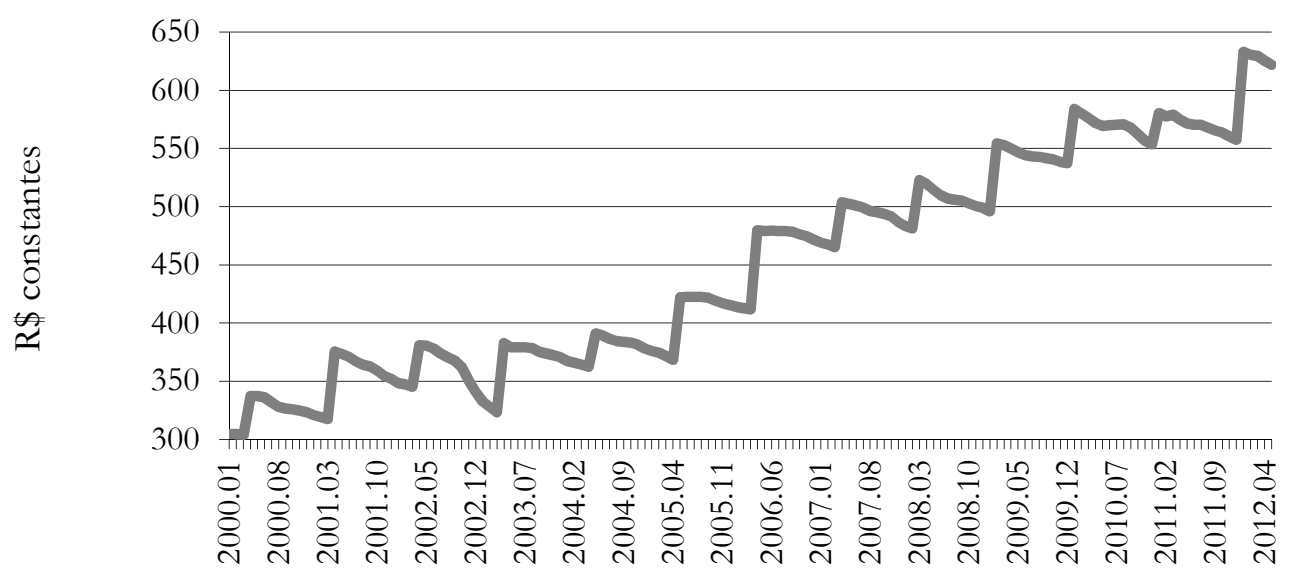

Mês e ano

Fonte: Instituto Brasileiro de Geografia e Estatística (IBGE) (deflacionado pelo INPC - Índice nacional de Preços ao Consumidor). 
Como se observa, no período de 2000 a 2011 o salário mínimo dobrou de valor e como esse é a base para diversas categorias de trabalhadores essa elevação atendeu a população mais pobre. Ademais, em um período de baixa inflação, em contraste com o observado na década de 1980 e 1990, as oscilações e a perda de poder de compra entre as datas de reajuste também foram menores, alavancando o consumo das classes populares e transformando esse aumento real no motor de um círculo virtuoso de crescimento.

As taxas de desocupação do período confirmam o aquecimento da demanda. Comparandose o final do ano de 2002 com o final de 2011, verificase que a taxa de desocupação geral da economia caiude $12,6 \%$ para $6,0 \%$. Nem mesmo a crise financeira internacional que irrompeu em 2008 reduziu a tendência geral de queda do emprego, embora a taxa de desocupação tenha oscilado um pouco para cima. Em adição ao crescimento do emprego, a última década registrou um aumento da formalidade dos trabalhadores. Em 2001 apenas 45,5\% dos trabalhadores tinham registro profissional, com o empregador e empregado recolhendo impostos diretamente no seu trabalho principal. Em 2011 essa proporção sobe para 59,2\% como resultado de uma maior pressão da demanda por trabalhadores no mercado.
Outro fator que contribuiu para o aumento da renda e do consumo das famílias foi o Programa Bolsa Família. Esse programa é fruto da união, em nível federal, de todos os outros programas de transferência de renda. Por esse motivo, ao final de 2003 o Bolsa Família já nasce com mais de três milhões de famílias beneficiárias. Ao final de 2009 o programa cumpre a meta de estar presente em todos os 5.564 municípios do Brasil gerando uma cobertura geral em convênio com os poderes locais. Em 2011, com o novo governo, o programa se acelera com a "busca ativa" de famílias que supostamente estariam em condição de miséria e ainda não incluídas no programa. Com isso, ao final do ano atinge-se um novo recorde de 13.3 milhões de famílias beneficiadas (Figura 3).

A combinação de crescimento econômico e combate à pobreza por meio de programas de transferências de renda condicionadas e inserção produtiva permitiu uma melhora no poder aquisitivo da população. Estimativas realizadas pelo Instituto Brasileiro de Geografia e Estatística (IBGE) mostram que houve uma redução da pobrezasegundo critérios relativos e um aumento no poder de consumo. Os dados da Figura 4 demonstram que em 2001, um salário mínimo tinha capacidade de comprar 1,37 cestas de consumo na cidade de São Paulo. No início de 2012 a capacidade de compra de um salário mínimo sobe para 2,24 considerando a mesma cesta de consumo.

Figura 3. Brasil: Volume de recursos gasto e o número de famílias beneficiadas com o Programa Bolsa Familia(2004-10)

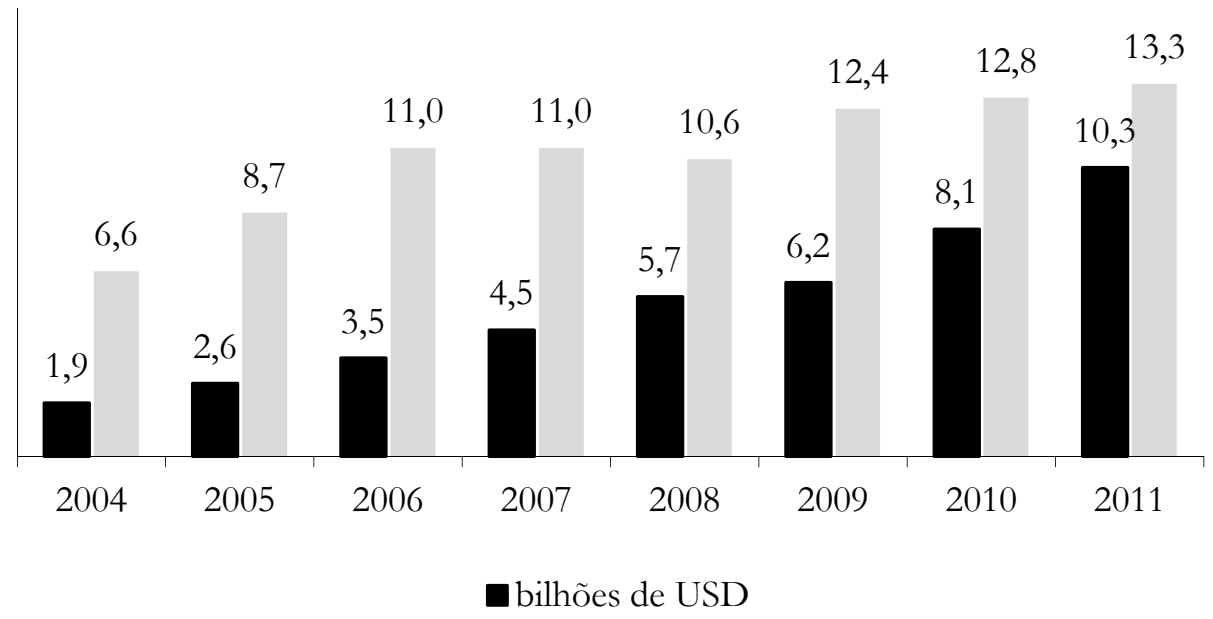

Fonte dos dados Brutos: Ministério do Desenvolvimento Social e Combate à Fome (MDS) ${ }^{14}$.

\footnotetext{
${ }^{14}$ Dados retirados do portal do MDS: http://aplicacoes.mds.gov.br/sagi/RIv3/geral/index.php (acesso em 02/12/2012). 
Figura 4. Brasil: Cestas básicas adquiridas com um salário mínimo (1995-12)

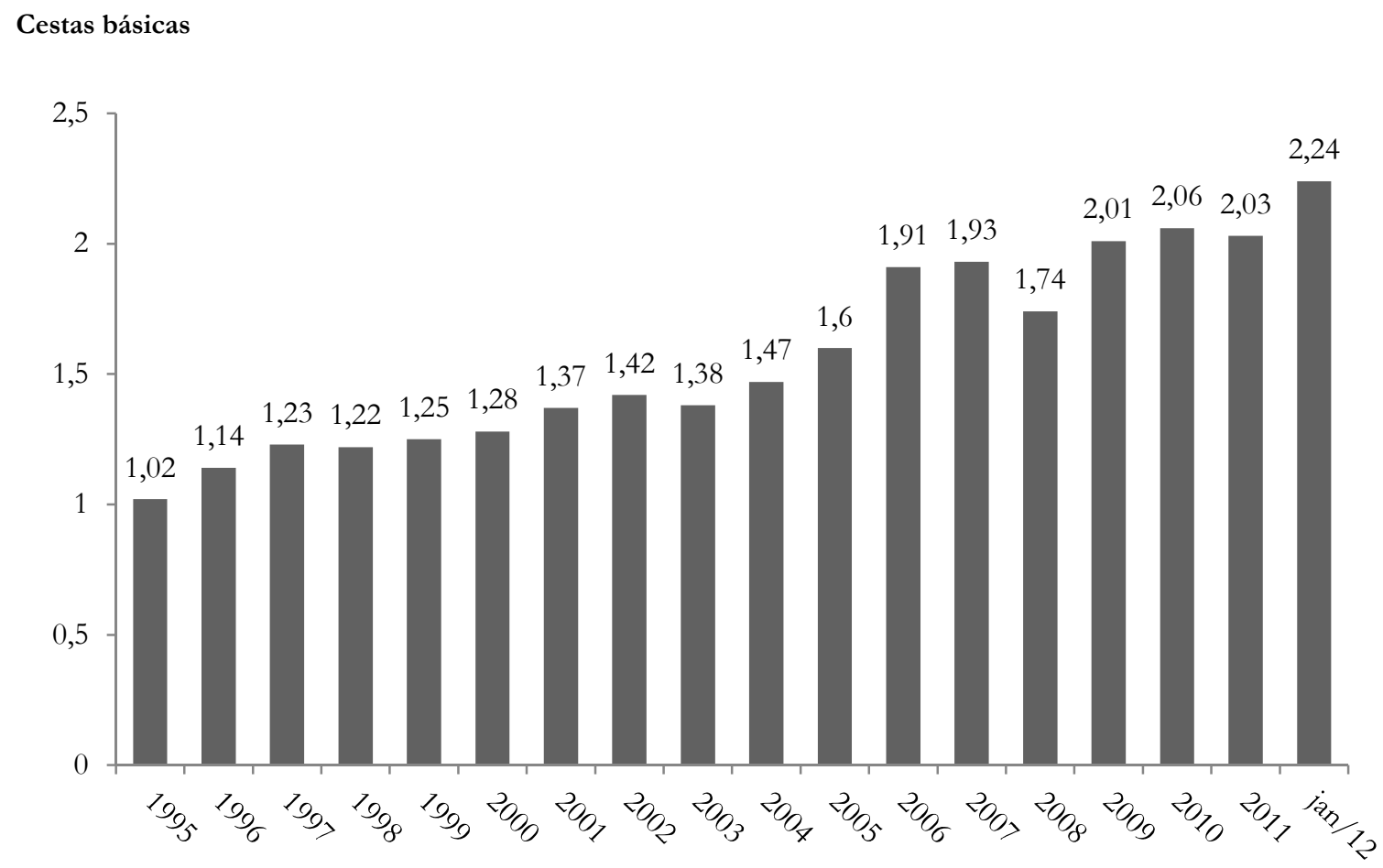

Observação: Cestas Básicas com provisões mínimas de alimentos, segundo o estabelecido no Decreto Lei no 399, de 1938, que regulamenta o Salário Mínimo.

Fonte: Departamento Intersindical de Estudos e Estatísticas (DIEESE).

Entretanto, considerando-se que houve uma elevação no salário mínimo, quando medimos a dimensão da pobreza em termos de salário mínimo, e levando-se em conta também o crescimento da população, observa-se que o número de familias que ficaram abaixo da linha da pobreza chegou até mesmo a aumentar. Segundo estimativas de Dedecca et al. [20], considerando-se a linha da pobreza referente à metade do salário mínimo real per capita vigente, o número de famílias abaixo da linha da pobreza aumentou de 13.043.345 em 2001 para 15.812 .850 em 2011. Entretanto, considerando-se a linha da pobreza de R\$ 70,00 per capita em termos reais, a mesma adotada recentemente para o planejamento do Brasil sem Miséria, o que representa um valor bastante próximo da estimativa de US\$ 1,25 per capita/dia, verificamos uma queda no número de famílias em pobreza extrema. Nesse caso o contingente de familias se reduziu de 4.900.116 milhões para 3.689.571 entre 2001 e 2009, anos para os quais os pesquisadores teriam informações do IBGE.
Outro indicador de destaque no período foi a redução na concentração de renda, pois não se observava mudanças significativas nesse indicador nas últimas décadas. Pelo contrário, com a hiperinflação dos anos 80 e início dos anos 90, a concentração de renda se agravou no Brasil. A Figura 5, apresentada a seguir, demonstra uma trajetória clara de desconcentração nas rendas do trabalho, entretanto vale mencionar que as informações sobre a concentração da renda em geral não demonstra uma queda tão acentuada, embora a tendência tenha sido mantida. Segundo cálculos preliminares realizados por Dedecca [21], o Índice Gini para todas as rendas se reduziu de 0,594 para 0,546 entre 2001 e 2009. A participação do primeiro décimo de renda da população sobre a renda geral aumentou de $0,4 \%$ para $0,6 \%$ enquanto a renda do décimo superior da população se reduziu de $42,7 \%$ para $38,9 \%$. 
Figura 5. Índice Gini do rendimento real de todos os trabalhos das pessoas com mais de 10 anos de idade ocupadas

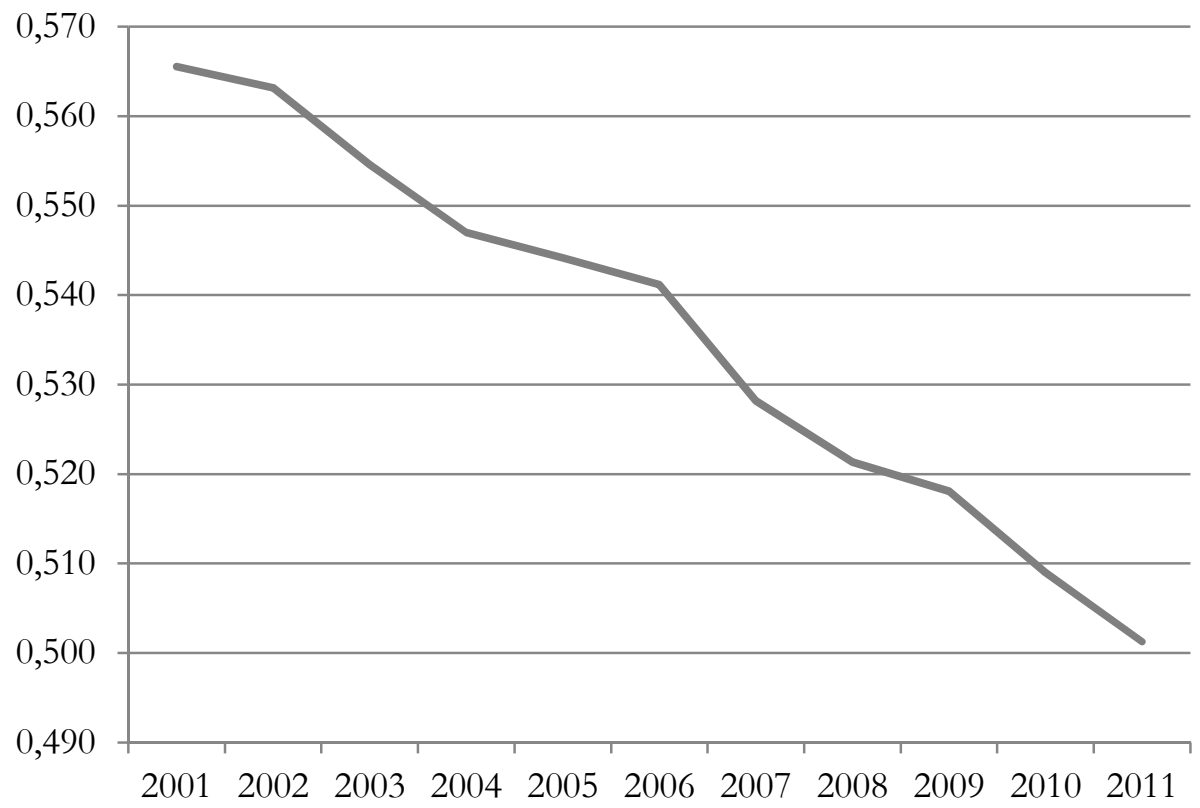

Obs: O ano de 2010 foi calculado por interpolação.

Fonte dos Dados Brutos: Instituto Brasileiro de Economia e Estatística (IBGE).

Alguns resultados na área de saúde e educação também merecem ser mostrados com o objetivo de reforçar o argumento de que o Fome Zero criou a possibilidade de funcionamento de um circuito virtuoso de crescimento.

A Figura 6 apresenta os resultados da taxa de mortalidade infantil no último período. Vale mencionar que a mortalidade infantil para crianças abaixo de cinconos de idade vem declinando no Brasil já há duas décadas. O que impressiona, no entanto é a velocidade de redução nos últimos anos. Em 2010, a mortalidade infantil caiu para 19,4 por 1.000 crianças nascidas vivas, sendo que nos estados mais desenvolvidos como São Paulo, esta se encontra com valores inferiores a um dígito.

Outro indicador importante verificado é com relação à redução no analfabetismo entre a população brasileira. Considerando-se a população de 15 anos ou mais, vale dizer: para a população em idade não escolar pela legislação brasileira, a porcentagem de analfabetos sofreu redução de 12,4\% para 8,4 \% entre 2001 e 2011. De uma forma geral o analfabetismo é um pouco maior entre os homens do que entre as mulheres. Outra característica é que entre as crianças em idade escolar a taxa de analfabetismo encontra-se em níveis quase residuais, sendo 2,8\% entre a população de 10 a 11 anos, 1,2\% entre a população de 12 a 14 anos e 1,2\% entre os jovens de 20 a 24 anos. Entretanto verifica-se um contingente expressivo de idosos (acima de 60\%) analfabetos. Em 2001 a proporção era de 34,0\%, reduzindo-se para 24,5\% em 2011, embora ainda bastante elevada ${ }^{15}$.

A Segurança Alimentar e Nutricional, elemento chave da política social desencadeada pelo Fome Zero também pode ser avaliada por um parâmetro específico que é o indicador de segurança alimentar, avaliado por meio da Escala Brasileira de Segurança Alimentar (EBIA), desenvolvida a partir do padrão norte-americano e latino-americano (ver PérezEscamilla et al., 2004 [22]; Segall-Corrêa \& Marin-Leon, 2009 [23]). Considerando as modalidades de insegurança alimentar moderada e grave, segundo a pontuação alcançada em pesquisa direta em uma amostra nacional de domicílios foi possível avaliar uma melhora entre os anos de 2004 e 2009. Observa-se na Tabela que o

15 Dados da Pesquisa Nacional de Amostragem Domiciliar (PNAD), do IBGE, 2004 e 2009. 
número de famílias em insegurança moderada ou grave declinou de 13,4 milhões para 7,5 milhões, o que representa uma proporção de $23,9 \%$ para $12,0 \%$ entre as duas datas.

Observa-se pela Tabela que considerando a linha da pobreza de $\mathrm{R} \$ 70,00$ em valores constantes ao longo do tempo, haveria um enorme contingente de famílias não pobres cuja situação de insegurança alimentar é moderada ou grave. Ademais, a grande concentração de famílias, em termos absolutos se encontra localizada em áreas urbanas metropolitanas e urbanas não metropolitanas (cidades médias e pequenas). Apesar dos níveis alarmantes de insegurança alimentar houve uma diminuição expressiva ao longo do tempo, principalmente entre os não pobres. Considerando o total de famílias não pobres a insegurança alimentar moderada e grave caiu de 20,3\% para 10,8\% entre 2004 e 2009, o que pode representar um aumento do nível de renda dessas famílias, mas também uma melhor consciência em relação ao consumo de alimentos. Já entre as famílias pobres a redução observada foi de $58,6 \%$ para $34,7 \%$, o que denota claramente uma maior participação dos programas públicos de alimentação, como a alimentação nas escolas, restaurantes populares, cozinhas comunitárias etc. na composição das refeições a que estas famílias têm acesso.

São muitas as vitórias conquistadas e quando analisamos os resultados do ponto de vista socioeconômico ou em termos dos indicadores de saúde e nutrição observa-se uma enorme melhora no caso do Brasil. No seu lançamento, o Projeto Fome Zero reunia um total de 25 políticas e 40 programas, a institucionalização dos mecanismos de execução, controle e acompanhamento dessas políticas e uma campanha emergencial para arrecadação de fundos e de alimentos. Parece evidente, portanto, que, em meio a grandes conquistas, algumas das propostas desenhadas no Fome Zero não progrediram. Nesse sentido, é importante destacar que alguns elementos apresentados no programa original não estiveram presentes ao longo desses anos seja por problemas institucionais na execução nos três níveis de governo que impediram a sua implementação, ou mesmo devido ao quase exclusivismo do Programa Bolsa Família que prevaleceu sobre os demais. Programas ligados ao abastecimento, educação alimentar e nutricional e agricultura urbana - para ficarmos nesses exemplos, não foram levados adiante, o que tem imposto dificuldades para o funcionamento de um sistema integrado de Segurança Alimentar e Nutricional.

Figura 6. Brasil: Mortalidade Infantil para nascidos vivos até 5 anos de idade (2000-10)

Valores em mil nascidos vivos

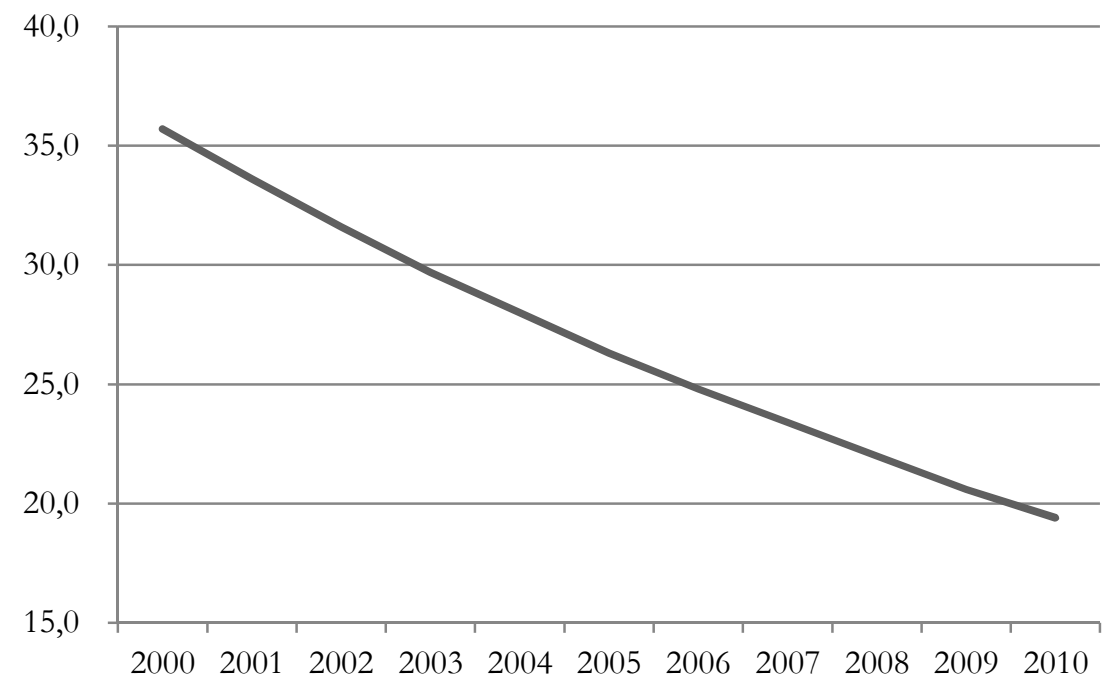

Fonte dos dados Brutos: Instituto Brasileiro de Geografia e Estatística (IBGE). 
: Tabela 1. Brasil: Evolução e número de famílias em insegurança alimentar moderada ou grave (EBIA) 2004-2009

\begin{tabular}{l|l|l|l|l|l|l|l|l|l|l|l|l}
\hline \multirow{2}{*}{ Área } & \multicolumn{4}{|c|}{ Pobres } & \multicolumn{4}{c|}{ Não Pobres } & \multicolumn{3}{c}{ Total } \\
\cline { 2 - 12 } & 2004 & $\%$ & 2009 & $\%$ & 2004 & $\%$ & 2009 & $\%$ & 2004 & $\%$ & 2009 & $\%$ \\
\hline
\end{tabular}

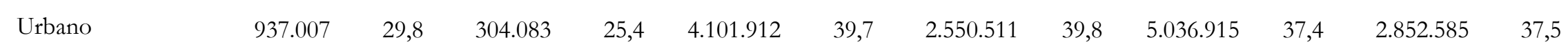

Metropolitano

\begin{tabular}{|c|c|c|c|c|c|c|c|c|c|c|c|c|}
\hline Urbano & 1.214 .948 & 38,7 & 472.449 & 39,8 & 4.422 .020 & 42,9 & 2.772 .904 & 43,3 & 5.636 .968 & 41,9 & 3.245 .353 & 42,7 \\
\hline \multicolumn{13}{|c|}{ Não metropolitano } \\
\hline Rural & 989.612 & 31,5 & 413.384 & 34,8 & 1.794 .221 & 17,4 & 1.085 .807 & 16,9 & 2.783 .833 & 20,7 & 1.499 .191 & 19,7 \\
\hline Total & 3.139 .563 & 100,0 & 1.187 .907 & 100,0 & 10.316 .149 & 100,00 & 6.407 .213 & 100,0 & 13.455 .712 & 100,0 & 7.595 .120 & 100,0 \\
\hline
\end{tabular}




\section{CONCLUSÕES}

Analisamos neste texto o processo de desenho do Projeto Fome Zero na forma como ele havia sido proposto pelo Instituto Cidadania em 2001. Vimos que o Fome Zero foi influenciado por uma larga tradição de estudos sobre a Segurança Alimentar e Nutricional e também pela mobilização popular dos anos 80 e 90. Mereceu destaque alguns comentários sobre a forma como o Fome Zero retrabalhou as questões ligadas à agricultura, ao abastecimento e à alimentação, dando a essas um caráter integrado. Por esse motivo, afirmamos que o Fome Zero foi o primeiro programa que conseguiu reunir todas as dimensões colocadas pela SAN em um Plano de Ação articulado.

$\mathrm{Na}$ segunda parte do artigo mostramos como o Projeto foi apresentado, com a separação de ações estruturais, específicas de alimentação e locais. Demonstramos a lógica interna desse arranjo e como esses programas poderiam trabalhar de forma complementar proporcionando o reconhecimento do Direito Humano à Alimentação para toda a população com uma alimentação saudável e nutritiva, preservando a dignidade da população. Para concluir demonstramos que o Fome Zero poderia avançar mais em algumas áreas que já estão relativamente bem estruturadas e institucionalizadas e que deveriam ter recebido uma atenção maior por parte dos governos e sociedade civil nos últimos anos.

\section{REFERÊNCIAS}

[1] Vasconcelos FAG. Combate à fome no Brasil: uma análise de Vargas a Lula. Rev Nutr. 2005;18(4):439-57.

[2] Costa C, Paqual M. Participação e políticas públicas na segurança alimentar e nutricional no Brasil. In: Garcés M, Giraldez S, Goldar MR, Albuquerque MC, Riquelme Q, Buroni T. Democracia y ciudadanía en el Mercosur. Santiago: LOM Ediciones/Programa MERCOSUR Social y Solidário; 2006. p. 319-32.

[3] L'Abbate S. As políticas de alimentação e nutrição no Brasil. Rev Nutr. 1988;1(2):87-138.

[4] Couto EP, Lisboa AM. Segurança alimentar e desenvolvimento no Brasil. In: VIII Encontro Nacional de Economia Política, 2003, Florianópolis. Anais... Florianópolis: SEP, 2003.

[5] Arruda BKG, Arruda IKG. Pobreza e desenvolvimento humano. Rev Bras Saúde Matern Infant. 2007;7(4):457-60.
[6] Declaração de Roma sobre a Segurança Alimentar Mundial e Plano de Acção da Cimeira Mundial da Alimentação [acesso em 04 dez 2012]. Disponível em: http://www.fao.org/docrep/003/w3613p/w3613p00.htm

[7] Fonseca A. Transferencia condicionada, estrategias de combate al hambre y la desnutrición en América Latina y el Caribe. Volumen I. Santiago do Chile: FAO; 2009.

[8] Lavinas L. Combinando compensatório e redistributivo: o desafio das políticas sociais no Brasil, IPEA. Texto para discussão no $748 ; 2000$.

[9] Andretta, Scott JR. Distribuição de subsídios alimentares no México In: Takagi M, Graziano da Silva J, Belik W. (Org.). Combate à fome e à pobreza rural. São Paulo: Instituto Cidadania; 2002. p. 109-30.

[10] Belik W. Políticas públicas, pobreza rural e segurança alimentar In: Fagnani E, Pochman M. (Org.). Mercado de trabalho, relações sindicais, pobreza e ajuste fiscal (Série Debates Contemporâneos: Economia Social e do Trabalho, no 1). São Paulo: LTr; 2007. p. 180-95.

[11] Bickel G, Andrews M. A evolução do programa de cupons de alimentação e a mensuração da fome dos Estados Unidos. In: Takagi M, Graziano da Silva J, Belik W. (Org.). Combate à fome e à pobreza rural. São Paulo: Instituto Cidadania; 2002. p. 33-74.

[12] Instituto Cidadania. Uma proposta de política de segurança alimentar para o Brasil. Projeto Fome Zero. São Paulo: Instituto Cidadania; 2001.

[13] Cohn A. Políticas sociais e pobreza no Brasil. Planejamento e Políticas Públicas. 1995;(12):1-17.

[14] Torres Filho ET, Carvalho ME. Uma análise dos programas de suplementação alimentar nos anos 80: desempenho e formas de organização. In: Ministério da Previdência e Assistência Social (MPAS); Comissão Econômica para a América Latina (CEPAL). Projeto: A política social em tempo de crise: articulação institucional e descentralização, vol. III: Avaliação das Políticas Sociais Brasileiras. Brasilia; 1989 (Relatório).

[15] Silva JG, Silva LIL. Política de segurança alimentar. São Paulo: Governo Paralelo, 1991. Não paginado. Mimeografado.

[16] Cunha ARA, Lemos MB, Nabuco MR, Pessoa M J. Políticas locais de acesso alimentar: entre a regulação e as políticas compensatórias In: Belik W, Maluf R. Abastecimento e segurança alimentar: os limites da liberalização. Campinas: IE/Unicamp; 2000. p. 183-210. 
[17] Coelho MP. (Coord.). A política de abastecimento alimentar da Prefeitura Municipal de Belo Horizonte. Relatório de Pesquisa IUPERJ/UFMG, 1996. Não paginado. Mimeografado.

[18] Nabuco MR, Guimarães LS. Ampliação da transparência e participação civil nos programas da Prefeitura de Belo Horizonte: COMUSAN. Projeto: "BH para o Século XXI". CEDEPLAR/Prefeitura de Belo Horizonte. Não paginado. Mimeografado.

[19] Belik W. Políticas de seguridad alimentaria para las áreas urbanas. In: Belik W. (Org.). Políticas de seguridad alimentaria y nutrición emAmerica Latina. São Paulo: Hucitec; 2004.p. 109-16.

[20] Dedecca CS, Belik W, Trovão CJBM, Flauzino de Souza L. A Questão social na primeira década do século XXI: conquistas e desafios. Cadernos de Estudos;
Desenvolvimento Social em Debate. Brasilia: Ministério do Desenvolvimento Social e Combate à Fome. No prelo.

[21] Dedecca CS. A queda da desigualdade de renda corrente e a participação do $1 \%$ de domicílios de maior renda. IE/Unicamp; 2012. Não publicado.

[22] Pérez-Escamilla, R, Segall-Corrêa AM, Kurdian ML, Archanjo SMF, Marín-León L, Panigassi G. An adapted versión of the U.S. Department of Agriculture Food Insecurity module is a valid tool for assessing household food insecurity in Campinas, Brazil. Communityand International Nutrition. American Society for Nutritional Sciences; 2004.

[23] Segall-Corrêa AM, Marin-Leon L. A segurança alimentar no Brasil: proposição e usos da Escala Brasileira e Medida da Insegurança Alimentar (EBIA); 2003-2009. Seg Alim Nutr. 2009:16(2):1-19. 